\title{
Do We Have a Trust Problem? Exploring Undergraduate Student Views on the Tentativeness and Trustworthiness of Science
}

\author{
William W. Cobern ${ }^{1}$ (D) Betty AJ Adams ${ }^{1} \cdot$ Brandy A-S. Pleasants $^{1} \cdot$ Andrew Bentley $^{2}$. \\ Robert Kagumba ${ }^{3}$
}

Accepted: 29 September 2021 / Published online: 9 January 2022

(C) The Author(s), under exclusive licence to Springer Nature B.V. 2021

\begin{abstract}
Science includes the fundamental attributes of durability and uncertainty; hence, we teach about the "tentative yet durable" nature of science. Public discourse can be different, where one hears both confidence about "settled science" and doubts about "just theories." The latter observation gives rise to the possibility that emphasis on learning the tentative nature of science offers some people the actionable option of declining to accept canonical science. Our paper reports the findings from initial and replication exploratory studies involving about 500 preservice, elementary/middle school teacher education students at a large Midwestern public university. Using a survey method that included opportunities for student comments, the study tested hypotheses about confidence in the veracity, durability, tentativeness, and trustworthiness of science. We found that most students embrace noncontroversial science as correct, and that almost all embraced the tentative nature of science regardless of what they thought about controversial topics. However, when asked about the trustworthiness of science, many students were not willing to say that they trust scientific knowledge. Even students strongly supportive of science, including controversial science, responded similarly. And why did they say that science is not trustworthy? The explanation echoed by many students was that scientific knowledge is tentative. Our paper concludes with implications for instruction and research. Our findings suggest that it would be prudent for science educators to increase instructional focus on the relationship between data and evidence that leads to the durability of scientific knowledge. Future research needs to thoroughly investigate the public interpretation of what we teach about the nature and characteristics of science, and for the implications it might have on how scientific knowledge is or is not incorporated in the development and implementation of public policy.
\end{abstract}

Keywords Nature of science $\cdot$ Trust $\cdot$ Public policy $\cdot$ Public understanding of science $\cdot$ Tentativeness Uncertainty

Science confronts a public crisis of trust. From the Oval Office in Washington and in news media around the world, the scientific consensus on climate change, the effective-

William W. Cobern

bill.cobern@wmich.edu

Extended author information available on the last page of the article 
ness of vaccines, and other important matters are routinely challenged and misrepresented. Doubts about science are sown by tobacco companies, the fossil fuels industry, free-market think tanks, and other powerful organizations with economic interests and ideological commitments that run counter to scientific findings. Yet we know that scientists sometimes make mistakes, and that particular scientific findings now widely believed will turn out to be wrong. So why, when, and to what extent should we trust science? Macebo (2019)

These are the opening lines in the introduction to Naomi Oreskes (2019) book titled Why Trust Science? Why indeed? While reading information supportive of climate change science, you may get the impression that it is "settled science"; of course, science is to be trusted. On the other hand, if you are reading something from a climate change skeptic, you may read that such science is "just a theory"; after all, how much trust should one place in science when we know that scientists make mistakes?

Given that the science education community strongly supports teaching the tentative nature of scientific knowledge, one might wonder if the skeptic has a legitimate argument. Scientists do make mistakes, and science claims no absolute truths. Writing about climate change consensus in 2004, Oreskes observed that "policy-makers and the media, particularly in the United States, frequently assert that climate science is highly uncertain" (p. 1686). Recalling what they learned at school regarding the tentative nature of science, dissenters may interpret repeated assertions of uncertainty as reinforcement that science is "highly tentative." In the same essay, Oreskes goes on to write that,

The scientific consensus might, of course, be wrong. If the history of science teaches anything, it is humility, and no one can be faulted for failing to act on what is not known.

But our grandchildren will surely blame us if they find that we understood the reality of anthropogenic climate change and failed to do anything about it. (p. 1686)

The dissenters and skeptics, however, will likely think that Oreskes wants to both have her cake and eat it too. After all, which is it? Science is humble and uncertain, or sturdy and trustworthy? Any scientific consensus can be wrong, and therefore the skepticism of dissenters is reasonable. It is sometimes even reassuring; otherwise, the scientific consensus on climate change would indicate an uncomfortable reality that must be addressed.

Experts will object that such justifications for skepticism are quite wrong, and that to draw such deductions is to misunderstand Oreskes' words, or worse, to distort her ideas. We agree; but we cannot help wondering to what extent emphasizing the tentative nature of scientific knowledge might undermine confidence in science, especially for those who have not grasped important epistemological nuances. Our paper reports the findings from an initial exploration of this possibility.

\section{Research Background}

Teaching the nature of science has become an important part of the science curriculum. While there is some disagreement as to exactly how the nature of science should be defined, most members of the science education research community agree that scientific knowledge is by nature tentative (e.g., McComas, 1998; for critical commentary, see Perla \& Carifio, 2008). A brief look at the literature indicates there are many studies focusing on how well students and teachers have embraced this idea. There are also many practical papers on how to teach the tentative nature of science. Moreover, 
there are published NOS studies that have investigated the acceptance of controversial concepts such as evolution and climate change as a function of NOS knowledge (e.g., Carter \& Wiles, 2014). There are NOS studies that have investigated "decision making on science and technology based issues" as a function of NOS knowledge (e.g., Bell \& Lederman, 2003, p. 352).

One also finds in the literature that certain scientific theories (especially in the USA), such as evolution and anthropogenic climate change, are rejected by significant portions of the public (Funk \& Kennedy, 2020; Masci, 2019). Often, one can find these scientific ideas criticized as "just theories," with the implication that the ideas are speculative and should not be acted on as if they represent accurate knowledge (see, for example, Lombrozo, 2012).

A central obstacle to accepting evolution, both among students and the general public, is the idea that evolution is "just a theory," where "theory" is understood in a pejorative sense as something conjectural or speculative. (Branch \& Mead, 2008, p. 287)

In his book "Only a Theory," Kenneth Miller reports overhearing the following:

This textbook contains material on evolution. Evolution is a theory, not a fact, regarding the origin of living things. This material should be approached with an open mind, studied carefully, and critically considered. (Miller, 2008, p. 2)

Such ideas, of course, indicate a misunderstanding of the scientific meaning of theory, and it's not surprising that the science community would rise in defense of science. Michela Massimi (2019, subtitle) asserts that "Truth is neither absolute nor timeless. But the pursuit of truth remains at the heart of the scientific endeavor," adding that,

The time for a defence of truth in science has come. It begins with a commitment to get things right. ... Climate science is true if what it says about $\mathrm{CO}_{2}$ emissions (and their effects on climate change) corresponds to the way that things are in nature.

And we science educators are not found faultless.

Perhaps a more pressing criticism of the way NOS is taught in schools is that it encourages rather too much doubt over scientific ideas. Many findings, after all, are well established and, indeed, taken as such by professional scientists who use them as shoulders to stand on. Not all science is tentative, and researchers should not be shy about saying so - both to those in schools and to those in charge of schools. (Nature., 2017, p. 149)

Giving serious attention to the concerns of the editors at Nature, we realize it is conceivable one might conclude that the inherently tentative nature of science means evolution or climate change ideas remain just that (tentative). We further wonder to what extent the science education community's focus on the tentative nature of science could actually be contributing to this misunderstanding of theory in science. The literature does not seem to contain studies that address any aspects of this concern, though as a science education community we recognize the urgency for a public understanding of what scientific theory means, and what it means when we say that science is tentative. We thus have begun a series of studies investigating the relationship between a person's commitment to science and understanding of the tentative nature of science.

This paper reports on initial and replication exploratory studies involving about 500 preservice, elementary/middle school (K-8) teacher education students at a large Midwest 
public university. Using a survey method that includes opportunities for student comments, the study initially tested two hypotheses:

Hypothesis (1): Students have confidence in the veracity of certain scientific concepts even if they have some doubts about areas of science such as evolution or climate change.

Hypothesis (2): Students who are less confident about the veracity of controversial concepts are likely to be more confident that scientific knowledge is tentative.

Bearing in mind the "just a theory" argument, we consider whether students who oppose or who are uncomfortable with controversial science concepts may bolster their doubts by turning to the inherently tentative nature of science. On the other hand, students who are confident in science overall may have a more nuanced view of the tentative nature of science. We address these possibilities through quantitative survey response means and correlations. Each student was also invited to make comments, and among those, we looked for evidence regarding how confidence in scientific ideas related to confidence in the inherently tentative nature of science.

\section{Methodology}

\subsection{Study Design and Instrumentation}

We ran an initial study followed by a replication study one year later. The design for both studies asked students about their confidence in scientific concepts that are not considered controversial, scientific concepts that are, and their confidence in the nature of science as tentative. The researchers are experienced college teachers of the life, physical, and earth sciences; and we drew on that experience to identify what we expected to be noncontroversial scientific concepts for typical undergraduate, non-science majors. There is a large body of noncontroversial science and so any number of appropriate statements could have been used. We decided to include two areas of noncontroversial science, but the choice of two was arbitrary (see Table 1); we could have chosen one or even three. Keeping the number low kept the instrument short, which is an important consideration when working with students.

Our choices for controversial science were similarly arbitrary, though not to the same extent. We picked the topics of human evolution and anthropogenic climatic change, both of which are amply documented by the literature as controversial in the public. We confirmed our choices by having them reviewed by other college teachers of science. We wanted to avoid presenting items that appeared to test knowledge, given that our interest is in confidence. Hence, we posed all items in the form of "according to the science community... "; and indeed, all of the statements are what might be called "settled science." The items were cast in a Likert format followed by a space for comments, a commonly used format by research organizations such as the Pew Research Center (e.g., Funk et al., 2020). For example: 
Table 1 Initial study statements, 2015

\begin{tabular}{l} 
Noncontroversial \\
$\begin{array}{l}\text { According to the science community, an object at rest stays at rest and an object } \\
\text { in motion stays in motion with the same speed and in the same direction unless } \\
\text { acted upon by an unbalanced force. } \\
\text { According to the science community, the heart pumps blood to the lungs where } \\
\text { oxygen is captured and then circulated throughout the body. } \\
\text { According to the science community, human activities are responsible for the } \\
\text { recent rapid increase of Earth's average atmospheric and oceanic temperatures. } \\
\text { According to the science community, all biological organisms, including humans, } \\
\text { have evolved over time from common ancestors. } \\
\text { According to the science community, scientific knowledge is durable, but can } \\
\text { change in light of new evidence or changes in perspective. }\end{array}$ \\
\hline
\end{tabular}

Please read the following scientific statement. Using the scale below, indicate how confident you are that the scientific statement is true. In the space below, briefly explain your choice of confidence level.

According to the science community, an object at rest stays at rest and an object in motion stays in motion with the same speed and in the same direction unless acted upon by an unbalanced force.

Not at all confident

Very confident

We used a nature of science statement commonly found in the literature representing the durable yet tentative nature of scientific knowledge (Lederman \& Lederman, 2014; McComas, 2020). The first chapter of Science for All Americans addresses the nature of science and includes the subheading "Scientific Knowledge is Durable." It goes on to explain that, "Although scientists reject the notion of attaining absolute truth and accept some uncertainty as part of nature, most scientific knowledge is durable" (AAAS, 1990; emphasis added). The science education community tends to use the word "tentative" in reference to the idea that scientific knowledge can change, whereas other academic communities such as the Public Understanding of Science, Science Communication, and Risk Analysis tend to use the word "uncertain" (on the latter, see, for example, Gustafson \& Rice, 2020, or Weisberg et al., 2020). Both terms indicate the potential for change. As stated by the AAAS (1990), Chapter 1),

Change in knowledge is inevitable because new observations may challenge prevailing theories. No matter how well one theory explains a set of observations, it is possible that another theory may fit just as well or better, or may fit a still wider range of observations.

One classic example for teaching that science is durable yet can change in light of new evidence (i.e., is tentative) is the shift from geocentrism to heliocentrism (DeWitt, 2018; Kuhn, 1957; Toulmin, 1961). For centuries, geocentrism was known to have theoretical and empirical veracity... until it didn't. Yes, for centuries it constituted durable scientific knowledge, but nevertheless this knowledge was always underdetermined, enhancing the possibility that future thinking and future evidence would cause changes to this "knowledge." Geocentrism was durable, yet always inherently tentative. Heliocentrism displaced geocentrism for theoretical and empirical reasons, and it has since been durable scientific 
knowledge for a very long time, yet in principle it too remains inherently tentative. Students who have an adequate understanding of the nature of science should be able to explain how it is that we can have confidence in scientific knowledge and yet still consider it ultimately tentative. The keys are knowledge and experience: a person understands the concept and has experience with it. We will return later to the keys of knowledge and experience when we elaborate on the concept of "trust."

Table 1 lists the five initial study statements. We did not consider the validity and reliability to be at all problematic. As a group, we have considerable experience with these students and the university and secondary curricula that they have studied. Our experience tells us that the concepts and the wording are familiar to the students. Furthermore, the questions are few and it would have been easy for students to ask questions about the items during administration, and, there was a section for comments that could indicate validity problems. Nothing during the administration of the items nor the analysis indicated problems, with one exception to be discussed below. Furthermore, we used a Likert approach that is common to market and public opinion research, again something to be discussed below.

\subsection{Replication Strategy}

The literature in recent years reports concerns that research too often is not substantiated through replication studies. Indeed, Makel and Plucker (2014, p. 304) "found that only $0.13 \%$ of education articles were replications." We sought to design our research in light of the concerns about replication. We quickly discovered, however, that "there are many different meanings to [replication] and the relevant procedures, but hardly any systematic literature" (Schmidt, 2009, p. 90). Among other forms, there is both direct and conceptual replication. Conceptual replication varies "one or more dimensions (e.g., population, setting, research design) from a prior study" (Chhin et al., 2018; also see Schmidt, 2009). Coyne et al. (2016), p. 247) suggest that in a conceptual replication of a prior study, researchers might vary such dimensions as the participants, setting, or outcome measures. Following Coyne et al. we adopted a conceptual replication strategy involving the variation of two outcome measures. We came to this decision based on findings of the initial study.

\subsection{Sample and Data Collection}

The samples for both studies were drawn from preservice, K-8 teacher education students enrolled in science content courses at a large Midwestern, public university. The courses were in the life sciences, physical sciences, and earth/space sciences, and they are specifically designed for K-8 teacher education. The students would have taken between one and three of these courses, with the clear majority having taken only one, the course they were in when providing data for this study. A much smaller number would have taken the second and third courses required of their program. These are content courses patterned on the Next Generation Science Standards (NGSS) and thus its three dimensions are prominent. There are activities that implicitly relate to both the tentative and durable nature of science, but little explicit nature of science instruction. It is important to note that this study did not test the impact of NOS instruction. We were examining what students think about science at this point in their school and university education. While they were not getting extensive nature of science instruction in their college science courses, many would have been exposed to nature of science instruction 
as high school students (given the curriculum in our State). Moreover, as denizens of the web, students in this age group could easily have encountered NOS concepts on the Internet. For example, we googled the "tentative nature of science" and found about a hundred thousand hits; searching for "nature of science" plus "tentative" returned about 5.8 million hits. We will return to the question of nature of science impact in our discussion of implications for future research.

The initial study had 305 student participants; the replication study had 202 student participants. There was no noticeable difference between the two cohorts; the vast majority of these students were typical primary/middle school $(\mathrm{K}-8)$ teacher education majors: overwhelmingly white, female, and just out of high school. Not more than $12 \%$ were males and not more than $10 \%$ were persons of color. Our research was limited in part by the traditional demographics of our sample pool. We refer to this later in the paper when discussing implications for future research.

Data collection for both studies took place over five days, spread out across three weeks as follows:

\begin{tabular}{|c|c|c|c|}
\hline \multirow[t]{2}{*}{ Week 1} & $1^{\text {st }}$ day & $\begin{array}{l}\text { Noncontroversial scientific statement: Newton's } \\
\text { First Law }\end{array}$ & (Abbreviated as Motion) \\
\hline & $2^{\text {nd }}$ day & $\begin{array}{l}\text { Controversial scientific statement: anthropogenic } \\
\text { climate change }\end{array}$ & (Abbreviated as Warming) \\
\hline \multirow[t]{2}{*}{ Week 2} & $3^{\text {rd }}$ day & $\begin{array}{l}\text { Controversial scientific statement: biological } \\
\text { evolution }\end{array}$ & (Abbreviated as Evolution) \\
\hline & $4^{\text {th }}$ day & $\begin{array}{l}\text { Noncontroversial scientific statement: heart/lung } \\
\text { function }\end{array}$ & (Abbreviated as Circulation) \\
\hline Week 3 & $5^{\text {th }}$ day & $\begin{array}{l}\text { Statement on the Nature of Science \& demographic } \\
\text { covariables: religiosity, science courses, politics, } \\
\text { age, gender }\end{array}$ & (Abbreviated as Durable/Tentative) \\
\hline
\end{tabular}

In the first two weeks, subjects were asked to respond to both noncontroversial and controversial statements about science. Data was collected in classes that met twice a week, with one question asked per class meeting. In the third week, the subjects were asked the NOS question(s) and also for their demographic information. The spacing was intended to help minimize subjects responding based on their previous item responses. The initial study returned the following means, with solid graph bars for the science items and a patterned bar for the NOS item (Table 2):

Table 2 Initial 2015 study of students' confidence (bar key: science, solid; NOS, patterned)

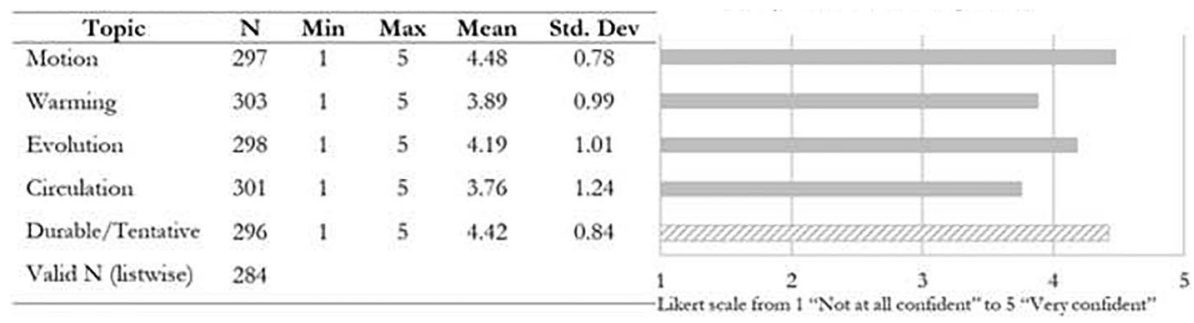




\subsection{Conceptual Replication}

The initial study was conducted in 2015. Since we were collecting data from several science courses taken by our preservice, K- 8 teacher education students, we ran the replication study in 2017 (a full academic year later) when the 2015 students had completed their science courses, and thus would not inadvertently end up in our replication study. We ran a conceptual replication in that we altered two outcome measures: the circulation item and the nature of science item. In 2015, we expected high confidence scores for the two noncontroversial science items. Instead, we found that, while the Motion item had the highest confidence score mean of all and the lowest standard deviation $(4.48,0.78)$, the Circulation item had a lower-than-expected confidence score mean (though still on the higher end of the scale as expected), with a high standard deviation $(3.76,1.24)$. Written comments from the students suggested that some may have misunderstood the circulation item. Faced with a possible validation problem, we wrote a new item deemed to have face equivalency with the original item, meaning "the extent to which items appear to be eliciting the same underlying knowledge facet, opinion or perception" (Taber, 2018, p. 1288). We wrote the new circulation item so that it addressed the same knowledge but with different words that we believed addressed the misunderstanding implicit in student comments (Table 3).

We also decided to rewrite the nature of science item, again employing the criteria of face equivalency. The original item was written using language commonly found in the literature of science education about the durable yet tentative nature of science, and we wanted students to respond to a common expression. However, that statement contains two clauses, and such double-clause statements are cautioned against in the survey methodology literature. We considered it worth our effort to unpack the two statements for the replication study.

We had two thoughts that guided our unpacking of the initial item on the durable yet tentative nature of science. We first noted that, while the initial mean for this item was high (4.42), student comments focused much more on the second clause: "scientific knowledge can change in the light of new evidence." Indeed, 79 students commented on this item, with $56(71 \%)$ comments stressing the second clause while only three students (4\%) stressed durability. Those stressing the tentative nature of science said things such as:

Science is always changing. (Student 2015-200)

I am very confident that this statement is true because information can always evolve which changes what was scientifically proven before. (Student 2015-82)

Science is tentative and every scientist has different views and ways of thinking. (Student 2015-60)

One student doubted the durability of scientific knowledge:

Science is done subjectively and is also tentative so I don't know if durable is the best word to describe it. (Student 2015-59)

Table 3 Circulation statements for 2015 and 2017

2015 According to the science community, the heart pumps blood to the lungs where oxygen is captured and then circulated throughout the body.

2017 According to the science community, circulating blood picks up oxygen as it passes through blood vessels in the lungs. 
Those stressing the durable nature of science said things such as:

Durable like a Ford F-150 (Student 2015-140)

We just learned this. It's robust! (Student 2015-121)

Of the 79 students commenting on the durable/tentative nature of science item, 15 (20\%) tied the two clauses together:

Science changes but the information is still reliable. (Student 2015-276)

Science can be durable, it is possible for an idea to withstand a long span of time. However upon new discovery science can also change quickly it's a situational process. (Student 2015-44)

All "knowledge" isn't $100 \%$ known as everything we know can change tomorrow. But, we are pretty sure on a lot of things. (Student 2015-26)

Science is tentative so it is subject to change. Yet until shown otherwise we hold to what is held true. (Student 2015-270)

Science changes but the information is still reliable. (Student 2015-275)

Most scientific information is collected and tested over a long time creating a consistent result. However this can change as technology progresses and new info is found. (Student 2015-304)

Although fewer than half of the students elected to write comments about this item, the 79 comments we got suggested that most students interpreted the statement to be about the tentative nature of science. Comments overwhelmingly in favor of the tentative nature of science added validity to our decision to split this question into two questions for the replication trial. Furthermore, scattered comments among the 79 suggested that some students did not understand what it meant that scientific knowledge could be durable.

Moreover, our further investigation of how students interpret the word "durable" in the context of scientific knowledge suggests that most students do not have a clear understanding of what this means (Adams et al., in preparation). As a group of scholars, our experience indicated that students hear more about tentativeness than about durability, which could reasonably explain why they seem to have a better understanding that scientific knowledge can change in the light of new evidence than they have that scientific knowledge is durable. The weight of student comments that focused solely on tentativeness corroborated our reasoning. Hence, for the conceptual replication, we looked for terms that suggested durability but were more accessible to the public. We decided on accuracy and trust (scientific knowledge is accurate and can be trusted, Table 4, 2017a). Knowing from our interactions with students and the public that trust is often extended because of who is providing information rather than the information itself, we added the word accuracy to encourage a focus on trust in the information or knowledge rather than trust in the person(s) bringing that knowledge. As will be discussed later, the data suggests that respondents ignored the word accuracy and focused on trust.

Table 4 Durable and tentative NOS statements for 2015 And 2017

2015 According to the science community, scientific knowledge is durable, but can change in light of new evidence or changes in perspective.

2017 (a) According to the science community, scientific knowledge is accurate and can be trusted.

(b) According to the science community, scientific knowledge can change in the light of new evidence. 
Voiced public concerns about certain areas of science such as evolution and climate change often make use of the terms "accuracy" and "trust." We are interested in the word "trust" because of its use in the public with respect to science, and because it seems plausible to us that something can be trusted if it is considered durable. These words are not synonyms for durable but they share semantic fields with durable. According to semantic field theory, words have elements of meaning shared by other words. The words that share that element of meaning can be grouped forming a semantic field (Johnson-Laird \& Oatley, 1989). Semantic fields are something that all people experience and indeed communication would be impossible without such fields. Across people, however, semantic fields are not identical although some elements of a field are likely to be more constant than others. Semantic fields are also highly sensitive to culture, which is one reason why a straight translation of words from one language to the other can be problematic. As an example, Ogawa (1986) addressed the problem of translating the English word "nature" into Japanese. The English word and the Japanese word often used in translation have significant semantic field differences, especially in a context about science.

We expect that trustworthy and durable have overlapping semantic fields. A thesaurus (e.g., Marriam-Webster, 2021) is an estimator of the words that constitute a semantic field. In a standard thesaurus, synonyms for something that is considered trustworthy (in other words, something in which we can trust) include reliable and dependable. Synonyms for durable also include reliable and dependable. The fields are not identical because the words are not identical but they share the meaning of being reliable and dependable. Shared words across two semantic fields can be of different types and yet share an element of meaning central to the field. We thus note that durability and trustworthiness are attributes of something (such as a scientific concept), while trust is a relational term with respect to some object (such as I trust science).

We can further specify that trust is a relational emotion; trust is a basic emotion. Our perspective on trust draws from basic emotions theory (Ekman, 1992), but we acknowledge that trust can be approached from a variety of other perspectives that at the least include philosophical/epistemological approaches and approaches from social economics (respectively, for example, Hardwig, 1991; and Reiersen, 2017). While various perspectives share a similar understanding of what "trust" means, within each perspective authors tend to draw on different sets of literature depending on whether the interest is, for example, philosophical or public opinion. On the other hand, one perspective can inform another (for example, philosophical tools can be used to unpack trust when it has been used as a basic emotion). It is because basic emotion theory underpins market/opinion research (Friend \& Tuddenham, 2015; Funk et al. 2020) that we find it of interest. When it comes to improving the public opinion of science, the venerable journal Science observed that the public generally does not have "faith in the scientific method" as do scientists, and that merely telling them to stop ignoring the facts, for example on climate change, "is juvenile, naïve, and ultimately ineffective" (Pittinsky, 2015 p. 511). On this point, there is something to be learned from market researchers. We are interested in public opinion about science and how to make science more attractive to the public; thus, we find it more appropriate to follow the lead of market/public opinion research.

According to basic emotion theory, emotions have "evolved through their adaptive value in dealing with fundamental life-tasks" (Ekman, 1992, p. 169). They are biologically basic and humans have them because historically they have been essential to survival (see, for example, Plutchik, 2001). While there is some disagreement about what these emotions include, there is little disagreement over many of these emotions such as fear, love, optimism, and trust. Drawing on basic emotion theory, market and opinion 
researchers thus consider it justifiable to ask the public simple questions such as, "do you trust this brand?" Or, "do you trust science?" See, for example, the many Edelman Trust (Edelman 2021) and Pew Research surveys (Pew Research Center, 2021).

As a basic emotion, people instinctively understand what is meant by trust. They know that it describes an emotion that we can feel about another person, resource, institution, or most any other thing. Our trust grows about things that we find to be lasting and durable; and the more we trust something, the more we are believing in its durability. Trust (as does distrust) comes through experience and knowledge, and in that sense, the word is similar to the idea of "durable" as we discussed above. I trust this person because I have had experience with this person and I have found them to be trustworthy. Hence, the common expression that "trust is earned." The Pew Foundation has done considerable work on public trust (e.g., Funk, 2017), and there is also the important work of the American Academy of Arts and Sciences (2018) on the public's perception of science that includes the concept of trust. Also see Sanz-Menéndez and Cruz-Castro (2019).

We thus connected trust as used in public opinion research with durable as used in nature of science research because they are conceptually related terms. As noted earlier, we say that scientific knowledge is durable when we understand a particular concept and we find that concept to have long-standing theoretical and empirical support. This explanation is very much like trust. Pertaining to the point of our work, trust in a belief is arguably one of the factors that leads one to qualify many of our firmest beliefs as "knowledge," particularly "scientific knowledge," whether that trust comes from experience, evidence, or testimony. Sometimes "has good reasons to believe" will strengthen into "knows," as between two versions of Hardwig (1991). Note that our NOS items all specify scientific "knowledge." It makes sense that if we find something durable, we will also say that we trust it. Of course, trust is not necessarily absolute; it has limitations. We trust our friends but not without limits. People do not typically assume that trust is always perfect and complete, because that would be too high a standard for any person or thing. Trust in science should not be seen any differently than this. Hence, polling and survey work tend to use Likert scales so that respondents indicate depth of trust or lack thereof.

The idea of science as being trustworthy can be found in the science education literature (see, for example, Allchin, 2020; Fasce \& Picó, 2019; Nadelson et al., 2014 \& Nadelson \& Hardy, 2015;). As noted at the beginning of this paper, Naomi Oreskes (2019) recently published a book titled, "Why Trust Science?" The lack of trust in science among some segments of the public is a serious hindrance to the implementation of science-based public policy. We think it is fair to say that if the public finds science to be durable, they will also find it to be trustworthy. We added the word "accurate" because we wanted the replication statement to include a reason for why science might be trustworthy. It is "accurate and can be trusted." We wanted to point the reader to an important aspect of science, undergirding why science can be trusted. Hence, we split the clauses into two items as follows:

We argue that the two 2017 NOS items have adequate face equivalency with the nature of science item in the 2015 study. The second clause wording of the 2015 item is kept for $2017 \mathrm{~b}$ as shown in Table 4. However, 2017a (Table 4) re-conceptualizes the durable aspect of science as science being accurate and trustworthy. The difference is that in the 2017 replication students responded to both parts of the 2015 item, except that 2017a brings greater clarity to the concept of durability by using terms more commonly found in public discourse, especially with respect to public policy. 


\subsection{Comparison of Data Samples}

We sought a detailed picture of the relative confidence levels of a large collection of students on a variety of statements about science. To accomplish this illustratively, we compared means and checked for correlations to explore the quantitative data with respect to our hypotheses. Given our large sample size, and the 5-point interval scale of our Likert items (where more means more, and the underlying concept of "degrees of confidence" is continuous), we chose to use parametric statistics for most overall analyses. The data exhibited acceptable normality based on skewness and kurtosis values. The two items "Science Changes" and "Motion" showed some negative skew (toward the right) and positive kurtosis (higher peak, more tail), as expected given their higher means and lower standard deviations. We also used both Pearson's test and Spearman's test to check for correlations, and they showed agreement.

Tests for significant differences between 2015 and 2017 indicate that the students in both years responded quite similarly. The mean for the climate change item was higher in 2017 than in 2015. The difference was statistically significant: $t(503)=2.133$, $p=0.033$. While this is a change in the right direction for the public understanding of anthropogenic climate change, the practical difference is fairly small, with both years affirming the statement. For the purpose of comparing the samples, based on comments we inferred that the 2015 nature of science statement was primarily read as a statement on the tentative nature of science, and thus could be compared with 2017b (Table 4). Here too, there was a statistically significant difference $\left(t\left(487.805^{*}\right)=4.970, p<0.001\right)$. However, the practical difference was again small, given that students in both years strongly affirmed the tentative nature of scientific knowledge.

What surprised us were the persistently low confidence scores on the circulation item; in fact, there was no statistical difference between the 2015 item (mean 3.76) and the revised 2017 item (mean 3.67). Our study had posited this item could serve as one of two noncontroversial concepts from science and thus we expected a relatively high and sturdy mean (recall, instead we found the lowest confidence mean and the highest standard deviation). The lower-than-expected confidence scores for the circulation item suggested that item validity was not at issue but that students' recollection about this noncontroversial topic was lacking, though they all were likely to have studied it at some point in middle or high school biology. This being the case, given that two items were not necessary for our purposes, we dropped the item from much of our summary analysis and reporting.

\section{Discussion of Findings}

Table 5 shows the items included for analysis along with their descriptive statistics, followed by a correlation table for the 2017 data which had two separate NOS items (Table 6). We display results for the motion item and NOS items for both years, with the 2015 nature of science item relabeled as regarding the tentative nature of science, that is, "science changes" (based on extensive feedback/comments). For Tables 2, 5, 7, and 8 , science item data is graphed in solid grayscale bars, while NOS item data bars are patterned/striped. All 2015 data bars are paler, and 2017 data bars are darker, to facilitate comparisons at a glance. 
Table 5 Comparing students' confidence for 2015 and 2017 (bar key: science, solid; NOS, patterned; 2015, pale; 2017, dark)

\begin{tabular}{|c|c|c|c|c|c|}
\hline Topic & Year & $\mathrm{N}$ & Mean & Std. Dev & \\
\hline \multirow{2}{*}{ Motion } & 2015 & 297 & 4.48 & 0.780 & 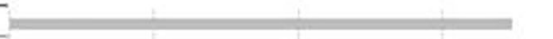 \\
\hline & 2017 & 202 & 4.49 & 0.793 & \\
\hline \multirow{2}{*}{ Warming } & 2015 & 303 & 3.89 & 0.986 & 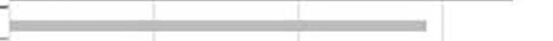 \\
\hline & 2017 & 202 & 4.08 & 0.948 & \\
\hline \multirow{2}{*}{ Evolution } & 2015 & 298 & 4.19 & 1.009 & 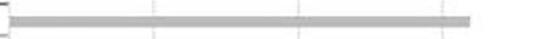 \\
\hline & 2017 & 201 & 4.11 & 1.104 & 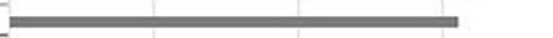 \\
\hline \multirow{2}{*}{ Changes } & 2015 & 296 & 4.42 & 0.840 & 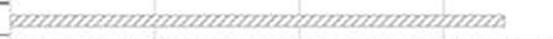 \\
\hline & 2017 & 194 & 4.73 & 0.539 & 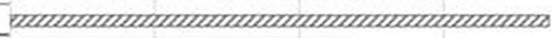 \\
\hline Trustworthy & 2017 & 195 & 3.37 & 1.088 & 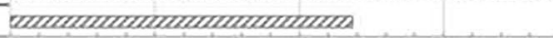 \\
\hline
\end{tabular}

Table 62017 correlations between students' confidence on different topics

\begin{tabular}{|c|c|c|c|c|c|c|}
\hline & & Motion & Warming & Evolution & Changes & Trustworthy \\
\hline \multirow[t]{3}{*}{ Motion } & Pearson's correlation & 1 & & & & \\
\hline & Sig. (2-tailed) & & & & & \\
\hline & $N$ & 202 & & & & \\
\hline \multirow[t]{3}{*}{ Warming } & Pearson's correlation & .004 & 1 & & & \\
\hline & Sig. (2-tailed) & .950 & & & & \\
\hline & $N$ & 200 & 202 & & & \\
\hline \multirow[t]{3}{*}{ Evolution } & Pearson's correlation & .039 & $.228^{* *}$ & 1 & & \\
\hline & Sig. (2-tailed) & .586 & .001 & & & \\
\hline & $N$ & 200 & 199 & 201 & & \\
\hline \multirow[t]{3}{*}{ Changes } & Pearson's correlation & .122 & $.184^{*}$ & .084 & 1 & \\
\hline & Sig. (2-tailed) & .092 & .010 & .247 & & \\
\hline & $N$ & 194 & 193 & 193 & 194 & \\
\hline \multirow[t]{3}{*}{ Trustworthy } & Pearson's correlation & .111 & .088 & $.158^{*}$ & .098 & 1 \\
\hline & Sig. (2-tailed) & .123 & .224 & .028 & .175 & \\
\hline & $N$ & 193 & 192 & 192 & 194 & 194 \\
\hline
\end{tabular}

*Correlation is significant at the 0.05 level (2-tailed). **Correlation is significant at the 0.01 level (2-tailed)

Table 7 NOS confidence in 2015 (light bars) and 2017 (dark bars) for students with low confidence $(1,2)$ and high confidence $(4,5)$ in Evolution

\begin{tabular}{|c|c|c|c|c|c|c|}
\hline Science... & Year & $\mathrm{N}$ & Men-Max & Mean & SD & \\
\hline Durable/Tentative & 2015 & 20 & $1-5$ & 4.25 & 1.07 & 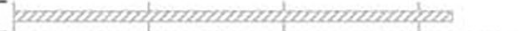 \\
\hline Changes & 2017 & 19 & $3-5$ & 4.68 & 0.58 & 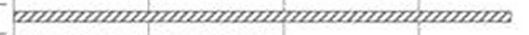 \\
\hline Trustworthy & 2017 & 19 & $1-5$ & 2.89 & 1.10 & 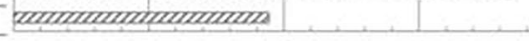 \\
\hline \multicolumn{6}{|c|}{ Higb Confidence $(4,5)$ in Erolution } & 2 \\
\hline Science... & Year & $\mathrm{N}$ & Min- Mfax & Mean & SD & \multirow{4}{*}{-1000000000000000000000000000000000000000} \\
\hline Durable/Tentative & 2015 & 236 & $1-5$ & 4.44 & 0.84 & \\
\hline Changes & 2017 & 149 & $2-5$ & 4.74 & 0.55 & \\
\hline Trustworthy & 2017 & 150 & $1-5$ & 3.44 & 1.09 & \\
\hline & & & & & & $1 \quad 2$ \\
\hline
\end{tabular}


Table 8 NOS confidence in 2015 (light bars) and 2017 (dark bars) for students with low confidence $(1,2)$ and high confidence $(4,5)$ in Warming

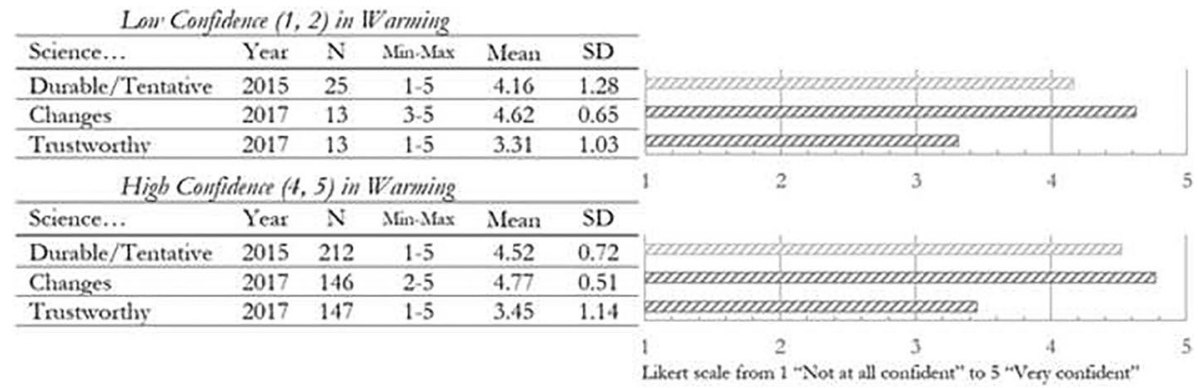

The comments made by students were categorized in light of our interest in evidence of student reflections on how confidence in scientific ideas relates to the inherently tentative nature of science.

Hypothesis (1): Students have confidence in the veracity of certain scientific concepts even if they have some doubts about areas of science such as evolution or climate change.

The good news is that all of the overall item means are right of center on the Likert scale (even for the problematic item on circulation). Moreover, the confidence scores for controversial science (evolution and climate change) do not correlate with the confidence scores for noncontroversial science, i.e., Newton's first law of motion. This suggests that even those who were less affirming of the controversial science still affirmed the noncontroversial science. This finding is consistent with other findings in the literature that people tend to be generally supportive of science even when there are aspects of science that they dispute.

Hypothesis (2): Students who are less confident about the veracity of controversial concepts are likely to be more confident that scientific knowledge is tentative.

The second hypothesis is central to the purpose of this study. We were concerned that emphasizing the tentative nature of science could inadvertently undercut confidence in science. We examined that concern in our research by looking at the relationship between confidence in controversial concepts vis-à-vis confidence in the tentative nature of scientific knowledge. The news is mostly good. There is a small statistically significant correlation between responses on the tentative nature of science and responses to the climate change item. There is also a small statistically significant correlation between the 2017 trustworthiness item and the evolution item. However, while statistically significant, these correlations are not strong, diminishing the likelihood of practical implications.

What strikes us foremost about the data is the overall change in responses to the NOS statements between 2015 and 2017 (illustrated by the three bottom graphic bars in Table 5, the first paler and the subsequent two darker). The mean in the 2015 data for the combined statement on the durability and tentativeness of scientific concepts is fairly strong (4.42). But, in the 2017 data with the NOS statement divided into a statement about change and a statement about trustworthiness, the two means diverge; the mean on the changeable nature of science rises (4.73) while the mean on trustworthiness drops markedly (3.37). 
We further examined the relationships between the controversial items and the trustworthiness and tentativeness of science by breaking out the means for those students showing low $(1,2)$ and high $(4,5)$ confidence with regard to the two controversial areas. Interestingly, the percentages do not change much over the two years of data collection. In both years, about $10 \%$ of the students indicated low confidence in human evolution, with about $74 \%$ (2015) and 81\% (2017) indicating high confidence. The means for anthropogenic climate change are similar. Just under $10 \%$ in both years indicated low confidence, while just over $70 \%$ in both years indicated high confidence. See Tables 7 and 8 .

Within these subgroups, again the divergent pattern is quite evident between 2015 (pale bars) and 2017 (darker bars); the confidence score means are moderately high when the concepts of durability/tentativeness are in a combined statement (2015), while the confidence score means for the separated statements (2017) are even higher for science as changeable and much lower for science as trustworthy.

Even students with high confidence on the controversial science topics are much more confident in the tentative nature of science than they are in the trustworthiness of science. For example, students with high confidence in climate change are not appreciably more confident in the trustworthiness of science than are students with low confidence in climate change. Perhaps unsurprising is the finding that students with low confidence in evolution are the least confident in the trustworthiness of science, with the only confidence score mean that falls below a neutral three on the Likert scale (2.89), even while their confidence in the tentative nature of science is rather high (4.68) (see upper portion of Table 7).

When we disaggregated the original compound statement about the durable yet changeable nature of science, it became evident that students are pretty clear that science is inherently tentative. It appears that all of the students have at least some confidence in the changeable nature of scientific knowledge. There were zero students who were "not at all confident" that science changes; all students who were highly confident of controversial science ranked the tentative nature of science at 2 or higher (lower portions of Tables 7 and 8). Moreover, all the students who expressed low confidence in controversial science ranked the tentative nature of science at 3 or higher (upper portions of Tables 7 and 8).

However, all students had much lower confidence in the durability (expressed as trustworthiness and accuracy) of scientific knowledge. It is much lower irrespective of their confidence in evolution and climate change science. We are conducting and will be reporting on additional investigations regarding terminology such as "durability" and "accuracy" and "trust." Careful language usage and explications are crucial in science education and associated research. Meanwhile, the uncomfortable possibility is that student commitment to the tentative nature of scientific knowledge may well be undermining their confidence in trustworthiness of science.

\subsection{What Students Had to Say}

The survey gave students an opportunity to comment about each statement. Given that our primary interest in this research was student understanding of the tentative nature of science in balance with the durability of scientific knowledge, we wanted to know whether students would comment on either idea with respect to the content statements. For example, we wanted to know if students affirming Newton's first law would support their affirmation by saying something about evidence or perhaps something about the tentative nature of scientific knowledge. For this aspect of our investigation, we categorized comments on content statements using categories arising from the comments: 
- Simple affirmation: such as "this is one of Newton's laws" or "we learned this in class," or restates or paraphrases the statement, or references theory or law such as "this is a law of physics, therefore it is true" (for our purposes, it did not matter that a student had a mistaken idea about theories and laws).

- Affirmation referencing evidence: affirms statement saying something about testing or observations.

- Dissent: offers some form of dissent from the statement.

- Don't know: comment in some form admits to not knowing.

- Misunderstanding: comment suggests that the student misunderstood the statement.

- Uninterpretable: comment is uninterpretable.

These categories were first developed by the lead researcher and then independently checked and approved by one of the co-researchers. This same procedure was used during the analysis. One researcher categorized comments with the second researcher independently checking and improving.

Although the two data collection episodes were conducted in the same way and with similar students, it was noticeable that in the first study fewer than one third of the students chose to comment while in the replication study the comment rate was at least doubled. We have been unable to discern any reason for this difference. However, the types of comments and ratio of comments are mostly similar across the two studies (Table 9). Hence, the discussion below is in reference to all of the data unless a specific year is mentioned.

For the Motion, Warming, and Evolution content there was little indication that students were either unfamiliar with the content or that they misunderstood the statement. It was the 2015 comments about Circulation that first indicated problems. A number of comments evinced misunderstanding of the statement or were some form of "I don't know." The wording change in 2017 reduced the number of students misunderstanding the statement

Table 9 Category percentages of science content comments (per year)

\begin{tabular}{|c|c|c|c|c|c|c|c|c|c|c|c|}
\hline \multirow[b]{2}{*}{ Comment category } & \multirow[b]{2}{*}{ Year } & \multicolumn{2}{|c|}{ Motion } & \multicolumn{2}{|c|}{ Warming } & \multicolumn{2}{|c|}{ Evolution } & \multicolumn{2}{|c|}{$\begin{array}{l}\text { Circula- } \\
\text { tion }\end{array}$} & \multirow{2}{*}{$\begin{array}{l}\text { Subtotals } \\
N\end{array}$} & \multirow{2}{*}{$\begin{array}{l}\text { Totals } \\
N\end{array}$} \\
\hline & & $N$ & $\%$ & $N$ & $\%$ & $N$ & $\%$ & $N$ & $\%$ & & \\
\hline \multirow[t]{2}{*}{ Simple affirmation } & 2015 & 67 & 83 & 47 & 51 & 45 & 63 & 44 & 57 & 203 & \multirow[t]{2}{*}{592} \\
\hline & 2017 & 122 & 86 & 103 & 67 & 87 & 62 & 77 & 61 & 389 & \\
\hline \multirow[t]{2}{*}{ Evidence-based affirmation } & 2015 & 9 & 11 & 5 & 5 & 11 & 15 & 3 & 4 & 28 & \multirow[t]{2}{*}{65} \\
\hline & 2017 & 9 & 6 & 4 & 3 & 22 & 16 & 2 & 2 & 37 & \\
\hline \multirow[t]{2}{*}{ Dissent } & 2015 & 0 & 0 & 37 & 40 & 12 & 17 & 1 & 1 & 50 & \multirow[t]{2}{*}{133} \\
\hline & 2017 & 3 & 2 & 41 & 27 & 30 & 21 & 9 & 7 & 83 & \\
\hline \multirow[t]{2}{*}{ Don't know } & 2015 & 5 & 6 & 3 & 3 & 1 & 1 & 13 & 17 & 22 & \multirow[t]{2}{*}{63} \\
\hline & 2017 & 6 & 4 & 0 & 0 & 0 & 0 & 35 & 28 & 41 & \\
\hline \multirow[t]{2}{*}{ Misunderstanding } & 2015 & 0 & 0 & 0 & 0 & 0 & 0 & 13 & 17 & 13 & \multirow[t]{2}{*}{15} \\
\hline & 2017 & 0 & 0 & 0 & 0 & 0 & 0 & 2 & 2 & 2 & \\
\hline \multirow[t]{2}{*}{ Uninterpretable } & 2015 & 0 & 0 & 0 & 0 & 2 & 3 & 3 & 4 & 5 & \multirow[t]{2}{*}{14} \\
\hline & 2017 & 2 & 1 & 5 & 3 & 1 & 1 & 1 & 1 & 9 & \\
\hline \multirow[t]{2}{*}{ Subtotals } & 2015 & \multicolumn{2}{|l|}{81} & \multicolumn{2}{|l|}{92} & \multicolumn{2}{|l|}{71} & \multicolumn{2}{|l|}{77} & \multicolumn{2}{|l|}{321} \\
\hline & 2017 & \multicolumn{2}{|l|}{142} & \multicolumn{2}{|l|}{153} & \multicolumn{2}{|l|}{140} & \multicolumn{2}{|l|}{126} & 561 & \\
\hline \multicolumn{2}{|l|}{ Totals } & \multicolumn{2}{|l|}{223} & \multicolumn{2}{|l|}{245} & \multicolumn{2}{|l|}{211} & \multicolumn{2}{|l|}{203} & & 882 \\
\hline
\end{tabular}


but increased the "I don't know" comments, countering our expectation that the affirmation comments would increase.

With few exceptions, comments correlated with the numerical data. Just as the majority of students affirmed confidence on all four of the science content statements $(=>3.5)$, a majority of the comments were also some form of affirmation. The statement of Newton's first law, for example, had the highest affirmation rate both quantitatively and qualitatively. Many affirming comments were about where students had learned the content. For example, students said that they learned about Newton's first law in their college physics class, or a few said that something (e.g., Newton's first law) was well-established in science. Very few of the Motion affirmation comments referenced evidence or anything associated with the nature of science. Similarly, with the Warming and Circulation statements, affirmations were most common, but very few students offered affirmations by reference to evidence or anything associated with the nature of science. On the other hand, affirmation comments about evolution were more likely to include something about evidence. For example, one student commented that "there is clear scientific evidence that backs this up, on both micro and macro evolution" (student \#2015-234), or "we have found bones and other remains to show(prove) that this is true" (student \#2017-168).

As for dissent on science content, as expected, few if any made dissenting comments about either the Motion or the Circulation statements. Again, as expected, almost all dissenting comments were in response to the controversial items, climate change and evolution. About evolution, for example, one student commented that data in support of human evolution is not that strong or that the data "was neutral" on the subject (student \#2015298); but other comments dissenting from evolution were about what people believe or don't believe. For example, "No, I don't because I do not believe in evolution" (student \#2015-208), or "Faith based reasons [for dissent]" (student \#2017-186). Most comments expressed outright rejection, as in "It depends if you agree with evolution or not..." (student \#2015-84), or “Because it doesn’t make sense” (student \#2017-171).

Regarding anthropogenic climate change, some students dissented by offering a different explanation, for example, "The earth warms in cycles of 11 years, so we may be in the warming point" (student \#2015-154), or "Not confident because the Earth goes through 11 year cycles where the Earth naturally warms" (student \#2017-160). Most dissenting students commented that there are reasons for climate change other than those attributed to humans. For example, "I chose to stay in the middle because I think there are other factors, not just human activities" (student \#2015-81), or "I feel like humans are responsible, but there are other factors involved as well" (student \#2017-30). Unlike dissenting comments on evolution, no one dissented simply in terms of what people believe or don't believe.

In summary, with respect to the primary interest of our research, we found few science content comments that were clearly informed by an understanding of the nature of science. When students did mention data, evidence, or observation (whether in affirmation or dissent), there was little equivocation that would suggest uncertainty or the tentative nature of the knowledge but rather implied that the knowledge was either accurate or not. We thus turned to what students had to say when they were asked directly about the durable, tentative, or trustworthy nature of scientific knowledge in general.

In both cycles of the study, students were asked to respond on a Likert scale to a question (2015) or questions (2017) about their confidence in scientific knowledge, couched in common science education language about durability and tentativeness. In both cycles, students were given the opportunity to elaborate on their responses if they felt it was needed. Although we rewrote the 2015 question as two questions for 2017, we developed a common categorization scheme arising from the comments. Because we 
used a common categorization, both "durable" and "trustworthy" appear in the category descriptions. The counts and percentages for these categories are presented in Table 10.

Given that the 2017 replication asked two separate questions, in addition to having a comment box for each of the two questions, there was a third box where students could explain how those two responses related to each other. Since the 2017 survey separately asked about the trustworthy and the tentative nature of scientific knowledge, the third comment box was important for collecting any student thoughts on the two concepts in combination. The comments in all three boxes were categorized as follows:

- Durable yet tentative: Identification of comments describing scientific knowledge as a combination of tentative yet durable or trustworthy.

- Tentative: Identification of comments speaking to the tentative nature of scientific knowledge.

- Durable/trustworthy: As per our discussion earlier, we equated the concepts of "durable" and "trustworthy." Identification of comments speaking to the durable or trustworthy nature of scientific knowledge.

- Uninterpretable, or not sure, or don't know: Identification of uninterpretable comments or comments that in some form admit to not knowing.

The above categories are shown in the left-hand column of Table 10. In the top row, the 2015 nature of science question is summarized as "durable yet tentative" column. The next three columns represent the question about the tentative nature of scientific knowledge, the question about accuracy and trustworthiness, and students' explanations of how they answered the questions about accuracy and trustworthiness vis-à-vis the tentative nature of science.

We noted earlier in the paper that, although the 2015 question asked about durability and the tentative nature of science together, we found the comments were overwhelmingly about the tentative nature of science. Even with the concepts broken out in the 2017 survey, the results are not very different. Forty of the 142 comments (28\%) concerning the accuracy and trustworthiness of scientific knowledge were specifically supportive, for example:

Scientific knowledge can be trusted because it goes through many phases before being considered widely accepted. (student \#2017-38)

Table 10 Category percentages of NOS comments (per year)

\begin{tabular}{|c|c|c|c|c|c|c|c|c|c|}
\hline \multirow[b]{3}{*}{ Comment category } & \multirow{2}{*}{\multicolumn{2}{|c|}{ 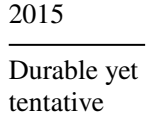 }} & \multirow{2}{*}{\multicolumn{2}{|c|}{$\frac{2017}{\text { Tentative }}$}} & \multirow{2}{*}{\multicolumn{2}{|c|}{$\begin{array}{l}2017 \\
\begin{array}{l}\text { Accurate/trust- } \\
\text { worthy }\end{array}\end{array}$}} & \multirow{2}{*}{\multicolumn{2}{|c|}{$\frac{2017}{\text { Explanation }}$}} & \multirow{3}{*}{$\begin{array}{l}\text { Total } \\
N\end{array}$} \\
\hline & & & & & & & & & \\
\hline & $N$ & $\%$ & $N$ & $\%$ & $N$ & $\%$ & $N$ & $\%$ & \\
\hline Durable yet tentative & 15 & 19 & 0 & 0 & 31 & 22 & 63 & 38 & 109 \\
\hline Tentative & 55 & 71 & 127 & 97 & 66 & 46 & 85 & 51 & 333 \\
\hline Durable/trustworthy & 3 & 4 & 2 & 2 & 40 & 28 & 14 & 8 & 59 \\
\hline $\begin{array}{l}\text { Uninterpretable, not } \\
\text { sure, don't know }\end{array}$ & 5 & 6 & 2 & 2 & 5 & 4 & 3 & 2 & 15 \\
\hline Total $N$ & 78 & & 131 & & 142 & & 165 & & 516 \\
\hline
\end{tabular}


Because science knowledge is tested, \& proven. Therefore it can be trusted \& reliable upon (student \#2017-83)

However, 66 of 142 comments (46\%) about the same question were specifically about the tentative nature of scientific knowledge, with no mention of durability, accuracy, or trustworthiness. For example:

Science is tentative, so it is subject to change. (student \#2017-47)

Scientific knowledge can always be changed due to new discoveries and experiments. (student \#2017-27)

The balance of the comments (31 of 142 or $22 \%$ ) was of a durable-yet-tentative nature. For example:

It can be trusted, but might change. What they see is happening, the reason why might change. (student \#2017-188)

Scientific knowledge is ever changing and evolving. There are known things that we can trust but scientists are always trying to learn more. (student \#2017-32)

In other words, when specifically asked about the trustworthiness of scientific knowledge, a majority of students either ignored this concept and instead mentioned that scientific knowledge is tentative, or they acknowledged trustworthiness but with the qualification that scientific knowledge is nevertheless tentative.

On the other hand, responses to the question about the tentative nature of science were of an entirely different order, with 127 of 131 (97\%) of the comments affirming the statement that it is in the nature of scientific knowledge to be tentative. For example:

Science is always changing. (student \#2017-150)

Science is subject to change, tentative, creative, etc. (student \#2017-59)

The students had clearly absorbed the concept that scientific knowledge is by nature tentative. Furthermore, the majority of them responded that way whether they were asked specifically about the tentative nature of science or about the accuracy and trustworthiness of science. Even when asked to explain their comments on the accuracy/trustworthiness of science vis-à-vis their comments on the tentative nature of science, $51 \%$ still focused on the tentative nature of science with only $8 \%$ focusing on the accuracy/trustworthiness of science. The notable difference in the explanation comments is that $38 \%$ were some form of durable-yet-tentative.

A few examples are illuminating. The upper half of Table 11 provides the comments from the two students quoted above who emphasized the trustworthiness of science. The first column has their comments on the tentative nature of science; their comments on the trustworthiness of science are found in the second column. Clearly both students affirmed the tentative nature of science and yet were also able to affirm the accuracy and trustworthiness of scientific knowledge. The third column has the explanatory comments, and in both cases the students come to a rational explanation for how scientific knowledge can be trustworthy yet tentative.

By way of comparison, the lower half of Table 11 provides the comments from the two students quoted above who emphasized the tentative nature of science. As could be predicted from the percentages in Table 10, both students commented on the accuracy and trustworthiness of science by ignoring this aspect of science and instead commenting again on the tentative nature of science. Their comments in the explanation show the split opinion among students primarily focusing on the tentative nature of science. The first 
Table 11 Comparing comments

\begin{tabular}{|c|c|c|c|}
\hline & Tentative & Accurate/trustworthy & Explanation \\
\hline 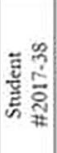 & $\begin{array}{l}\text { Science changes all the time } \\
\text { because of different experiments } \\
\text { and outcomes. }\end{array}$ & $\begin{array}{l}\text { Scientific knowledge can be trusted } \\
\text { because it goes through many phases } \\
\text { before being considered widely } \\
\text { accepted. }\end{array}$ & $\begin{array}{l}\text { They relate because scientific } \\
\text { knowledge could be accurate at the } \\
\text { time but if new information stufaces, } \\
\text { what is known can change/alter } \\
\text { previous assumptions. }\end{array}$ \\
\hline 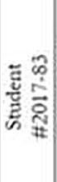 & $\begin{array}{l}\text { Because if more evidence are } \\
\text { discovered in the future, it'll } \\
\text { definite change the previous } \\
\text { knowledge we have est. }\end{array}$ & $\begin{array}{l}\text { Because science knowledge are } \\
\text { tested, \& proven. Therefore it can be } \\
\text { trusted \& reliable upon. }\end{array}$ & $\begin{array}{l}\text { So scientific knowledge are est. by } \\
\text { experiments, and other things. } \\
\text { However, more research \& discorery } \\
\text { come in the future making scientific } \\
\text { knowledge change in the course of } \\
\text { time. }\end{array}$ \\
\hline 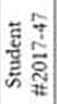 & Science is tentative. & $\begin{array}{l}\text { Science is tentative, so it is subject to } \\
\text { change. }\end{array}$ & $\begin{array}{l}\text { They both have to do with scientific } \\
\text { knowledge and the potential for it to } \\
\text { change. }\end{array}$ \\
\hline 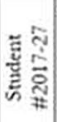 & $\begin{array}{l}\text { Yes, because if new evidence } \\
\text { changes a theory then it's the new } \\
\text { evidence, new technology helps us } \\
\text { do this. }\end{array}$ & $\begin{array}{l}\text { Scientific knowledge can always be } \\
\text { changed due to new discoveries and } \\
\text { experiments. }\end{array}$ & $\begin{array}{l}\text { Scientific knowledge is accurate and } \\
\text { can be trusted until new eridence } \\
\text { changes those things }\end{array}$ \\
\hline
\end{tabular}

student's only specific comment is about the tentative nature of science. In contrast, the second student reasonably ties the two ideas together even though the student's comment on the accuracy and trustworthiness of nature focuses on the tentative nature of science. The difference between these two students is indicative of how the ratio in Table 10 for the explanation comments shifts, from the tentative nature of science emphasis one sees in the comments regarding the other two questions, toward a somewhat more balanced emphasis when students are asked to consider the two aspects of science together.

Examining frequencies of comment types on science content (Table 9) and nature of science content (Table 10), we find no simple correlation of commitment to the tentative nature of science with commitment to science content, whether controversial or not. From this perspective, Hypothesis (2) cannot be supported. The analysis does not support the conclusion that students less confident about the veracity of controversial concepts are likely to be substantially more confident that scientific knowledge is tentative. Instead, students of all stripes are widely supportive of the tentative nature of science and reluctant to describe science as trustworthy or even accurate. Recalling Table 6, the comments align with the quantitative finding of only two statistically significant correlations between responses about controversial science and responses about the tentative or trustworthy nature of science. At that, these correlations are weak, suggesting little practical importance.

The number of dissenting students is low, with only 20 (in 2015) and 19 (in 2017) on evolution (Table 7), and only 25 (in 2015) and 13 (in 2017) on climate change (Table 8). These numbers are too low for there to be practically meaningful statistical correlations. On the other hand, comments from these few students can still be instructive. Hence, our final analysis in response to Hypothesis (2) that students less confident about the veracity of controversial concepts are likely to be more confident that scientific knowledge is tentative looked specifically at the comments coming from students represented by Table 7 and 8 . These tables show that the mean responses to the nature of science questions differ 
considerably when broken out by students with low confidence in evolution or climate change vis-à-vis those with high confidence. Tables $12,13,14,15$ provide example comments from these students. These tables represent the students who most dissented from the controversial statements and those who most accepted them. We chose these students based on their Likert scores (scores of 1 and 2 vis-à-vis scores of 5). Although not every student commented and not every student who commented did so on all items, these comments are typical of the comments coming from students who dissented and students who accepted.

Dissent to the evolution statement was strongest and the reasons for dissent were typically religious (Table 12). The demographic data we collected showed few differences with respect to student scores or comments with the exception that students who indicated regularly attending religious services showed less confidence in human evolution.

For the evolution dissenters in the 2015 group $(N=20)$, comments on the durable yet tentative nature of science question had to do with the tentative nature of science and not the durable nature. Similarly, in the 2017 data $(N=19)$, evolution dissenters focused on the

Table 12 Evolution dissent comments, 2015 and 2017

\begin{tabular}{|c|c|c|c|c|}
\hline \multicolumn{5}{|c|}{2015 Evolution dissent comments } \\
\hline & Score & Evolution & Score & Durable yct tentative \\
\hline 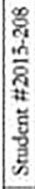 & 1 & $\begin{array}{l}\text { No, I don't because I } \\
\text { do not believe in } \\
\text { crolution. }\end{array}$ & 5 & $\begin{array}{l}\text { Science is always } \\
\text { changing when new } \\
\text { things come along to } \\
\text { prove something or } \\
\text { make something } \\
\text { false. }\end{array}$ \\
\hline$\frac{\Re}{n}$ & 2 & $\begin{array}{l}\text { Not all animals have } \\
\text { the fall, and in the } \\
\text { Bible it says God } \\
\text { created Adam \& Eve } \\
\text { so I don't think } \\
\text { humans evolved } \\
\text { from something else } \\
\text { cither. }\end{array}$ & 2 & $\begin{array}{l}\text { Science is done } \\
\text { subjectively and is } \\
\text { also tentative so } 1 \\
\text { don't know if durable } \\
\text { is the best word to } \\
\text { describe it. }\end{array}$ \\
\hline
\end{tabular}

2017 Evolution dissent comments

\begin{tabular}{|c|c|c|c|c|c|c|c|}
\hline & Score & Evolution & Score & Tentative & Score & $\begin{array}{l}\text { Accurate and } \\
\text { trustworthy }\end{array}$ & Explanation \\
\hline 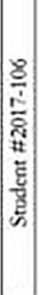 & 1 & $\begin{array}{l}\text { It is possible that } \\
\text { humans could have } \\
\text { evolved but I believe } \\
\text { that the starting } \\
\text { point of the Earth } \\
\text { started with God! } \\
\text { But I don't think } \\
\text { plants and humans } \\
\text { cvolved from the } \\
\text { same thing. }\end{array}$ & 5 & $\begin{array}{l}\text { Data \& cvidence } \\
\text { always changes as we } \\
\text { leam new research } \\
\text { techniques \& as } \\
\text { technology } \\
\text { inventions arc } \\
\text { constantly being } \\
\text { created. }\end{array}$ & 2 & $\begin{array}{l}1 \text { do not put my faith } \\
\text { or belicfs solely in } \\
\text { science because it } \\
\text { constantly changes. }\end{array}$ & $\begin{array}{l}\text { Student } 2017-106 \\
\text { mads no camment to } \\
\text { oplain the other tave } \\
\text { comments }\end{array}$ \\
\hline 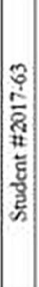 & 1 & $\begin{array}{l}\text { I am a believer of the } \\
\text { Bible, so I don't } \\
\text { agree with this } \\
\text { commonly accepted } \\
\text { idea. I believe that } \\
\text { God created this } \\
\text { world. I do not } \\
\text { belicve we cvolved } \\
\text { from apes or other } \\
\text { animals. }\end{array}$ & 5 & $\begin{array}{l}\text { Student } 2017.63 \\
\text { made no comment }\end{array}$ & 3 & $\begin{array}{l}\text { Science is always } \\
\text { changing. } A \text { trusted } \\
\text { picce of knowledge } \\
\text { can change as } \\
\text { technology advances. }\end{array}$ & $\begin{array}{l}\text { They relate because } \\
\text { we are constantly } \\
\text { learning new things. } \\
\text { Therefore, previous } \\
\text { knowledge can/will } \\
\text { change as new info } \\
\text { is obtained. Scicnce } \\
\text { is tentative. }\end{array}$ \\
\hline
\end{tabular}


Table 13 Evolution acceptance comments, 2015 and 2017

\begin{tabular}{|c|c|c|c|c|}
\hline \multicolumn{5}{|c|}{2015 Evolution acceptance cormments } \\
\hline & Score & Evolution & Score & Durable yet tentative \\
\hline 瓷 & 5 & $\begin{array}{l}\text { There are many } \\
\text { different forms of } \\
\text { evidence to prove } \\
\text { this in many } \\
\text { organisms. }\end{array}$ & 4 & $\begin{array}{l}\text { When new evidence } \\
\text { comes into light the } \\
\text { scientific community } \\
\text { tests it many times } \\
\text { and make sure it fits } \\
\text { if they are changing } \\
\text { perspective. }\end{array}$ \\
\hline 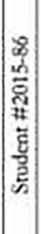 & 5 & $\begin{array}{l}\text { It is proven that a lot } \\
\text { of onganisms have a } \\
\text { lot of the same } \\
\text { features in their } \\
\text { DNA proving they } \\
\text { are closely related } \\
\text { and evolved from a } \\
\text { common ancestor. }\end{array}$ & 5 & $\begin{array}{l}\text { Scientific knowledge } \\
\text { is subject to change } \\
\text { when there is new } \\
\text { discoveries and new } \\
\text { evidence presented. }\end{array}$ \\
\hline
\end{tabular}

2017 Evolution acceptance comments

\begin{tabular}{|c|c|c|c|c|c|c|c|}
\hline & Score & Evolution & Score & Tentative & Score & $\begin{array}{l}\text { Accurate and } \\
\text { trustworthy }\end{array}$ & Explanation \\
\hline 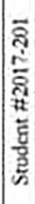 & 5 & $\begin{array}{l}\text { Everything evolves } \\
\text { from something, it } \\
\text { doesn't just come \& } \\
\text { appear out of } \\
\text { nowhere. }\end{array}$ & 5 & $\begin{array}{l}\text { When scientists } \\
\text { discover new things, } \\
\text { they can learn that } \\
\text { other/previous info } \\
\text { could have been } \\
\text { incorrect, so they } \\
\text { change it. }\end{array}$ & 5 & $\begin{array}{l}\text { Because scientists } \\
\text { continue to test it } \\
\text { until they know it's } \\
\text { correct/accurafe. }\end{array}$ & $\begin{array}{l}\text { They both relate to } \\
\text { scicntists work \& } \\
\text { how accurate their } \\
\text { info is. }\end{array}$ \\
\hline 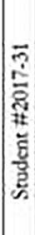 & 5 & $\begin{array}{l}\text { I definitely believe in } \\
\text { evolution and have } \\
\text { seen proof of it } \\
\text { occurring in my time } \\
\text { in school. }\end{array}$ & 5 & $\begin{array}{l}\text { I agrec completely in } \\
\text { my answer. } \\
\text { [to acct/trust } \\
\text { question] }\end{array}$ & 4 & $\begin{array}{l}\text { Science is subjective } \\
\text { and always changing. } \\
\text { For the most part, } \\
\text { we can trust it. }\end{array}$ & $\begin{array}{l}\text { Science is mostly } \\
\text { accurate, but } \\
\text { question [on } \\
\text { tentativeness] } \\
\text { validates that it can } \\
\text { change with new } \\
\text { cvidence \& } \\
\text { information. }\end{array}$ \\
\hline
\end{tabular}

changeable nature of science, even within their responses to the question about the trustworthiness of science. Looking at this group alone, data in the form of comments suggests that their strong view on the tentative nature of science couples with a dimmer view of the trustworthiness of science to buttress their dissent to evolution. Their comments track well with their Likert scores, and with the Likert score differences between those who strongly dissent from evolution and those who strongly accept it (Table 7).

As for those accepting of evolution (Table 13), their numbers were fortunately much greater (2015: $N=236$ out of $303 ; 2017: N=150$ out of 202), and their comments more diverse. For example, Student 2015-37 strongly accepts evolution and then comments on the multiple testing that goes on in science, seemingly in support of the durable nature of science while recognizing the possibility for change. In contrast, Student 2015-86, though also strongly accepting of evolution, comments only on the tentative nature of science in response to the durable yet tentative statement. Among the 2017 students, Student 2017201 at first comments that the testing of ideas leads to "correct/accurate" knowledge but then also acknowledges that new discoveries can change what scientists think is correct knowledge. Student 2017-31 at first focuses on the tentative nature of science but then comments that "science is mostly accurate." If there is a pattern in the comments made by 
Table 14 Climate change dissent comments, 2015 and 2017

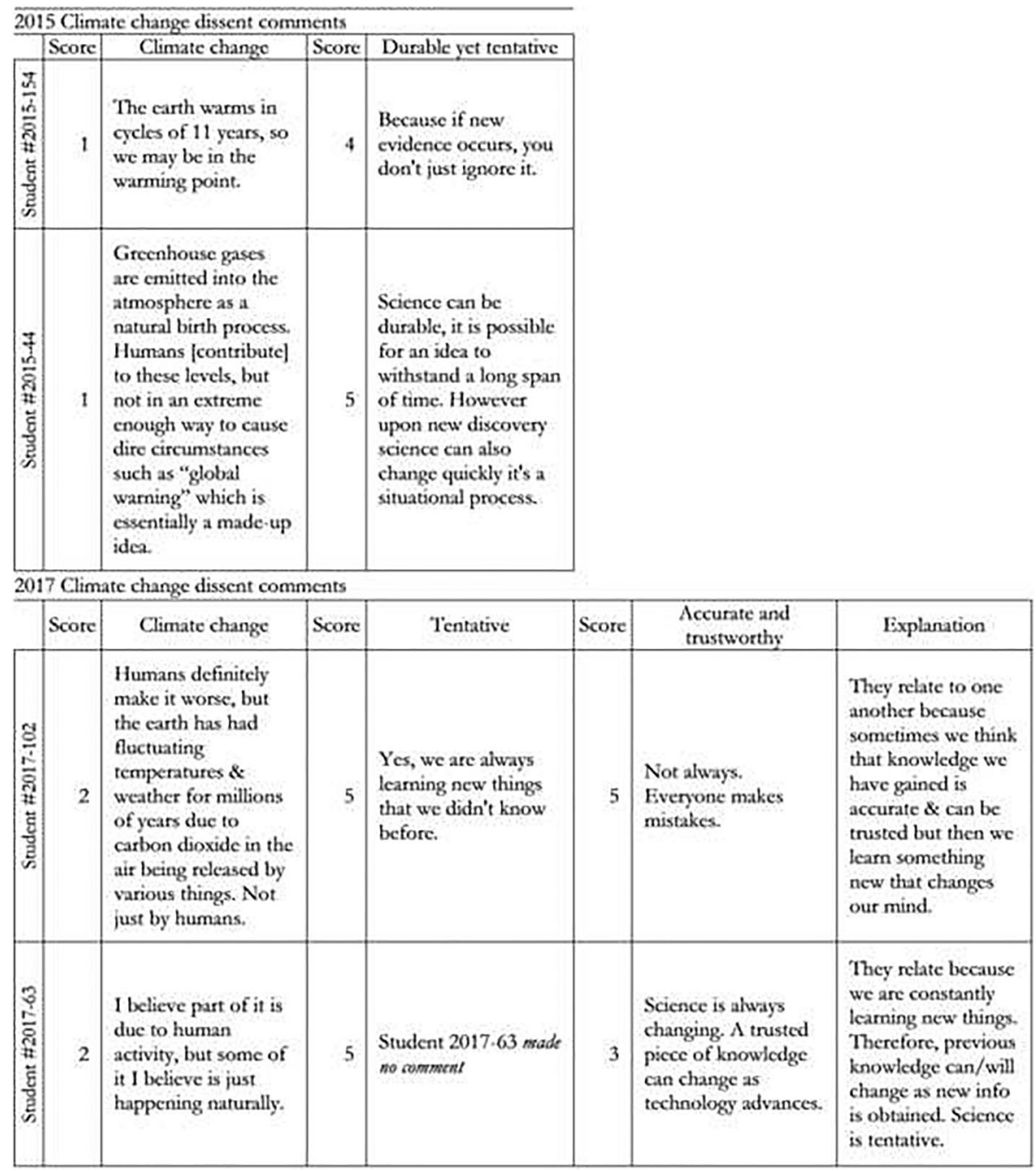

students accepting of evolution it is likely that they primarily recognize the tentative nature of science but not at the expense of accuracy, though trust is not a preferred term. As with the dissenting students, comments from the students who strongly accept evolution track well with their Likert scores. The strongest scores are for the tentative nature of science rather than the accuracy and trustworthiness of science, but their views on the accuracy and trustworthiness of science are still much stronger than those coming from the dissenters.

The ways in which the comments differ between the dissenters and accepters of evolution track well with the differences in their Likert scores. Both groups comment on the tentative nature of science and both groups have strong confidence (Likert means) on the tentative nature of science. The dissenters, in contrast to the accepters, indicate a lack of trust in scientific knowledge and that lack of trust appears implicitly to be related with their views on the tentative nature of science. However, while the accepters of evolution show 
Table 15 Climate change acceptance comments, 2015 and 2017

\begin{tabular}{|c|c|c|c|c|}
\hline \multicolumn{5}{|c|}{2015 Climate change aceeptance comments } \\
\hline & Score & Climate change & Score & Durable yet tentative \\
\hline 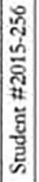 & 5 & $\begin{array}{l}\text { I have read about } \\
\text { this topic \& know } \\
\text { there is proof that } \\
\text { scientists have } \\
\text { cvidence for. }\end{array}$ & 5 & $\begin{array}{l}\text { Science can be } \\
\text { described as } \\
\text { tentative. }\end{array}$ \\
\hline 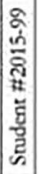 & 5 & $\begin{array}{l}\text { As humans create } \\
\mathrm{CO} 2 \text {, it increases the } \\
\text { greenhouse effect, } \\
\text { heating the earth. }\end{array}$ & 5 & $\begin{array}{l}\text { Ideas and discoveries } \\
\text { are always changing. } \\
\text { affecting what we } \\
\text { belicve. }\end{array}$ \\
\hline
\end{tabular}

2017 Climate change acceptance comments

\begin{tabular}{|c|c|c|c|c|c|c|c|}
\hline & Score & Climate change & Score & Tentative & Score & $\begin{array}{l}\text { Accurate and } \\
\text { trustworthy }\end{array}$ & Explanation \\
\hline 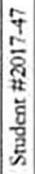 & 5 & $\begin{array}{l}\text { It has been shown } \\
\text { that human activities } \\
\text { increase global } \\
\text { temperatures. }\end{array}$ & 5 & Science is tentative. & 3 & $\begin{array}{l}\text { Science is tentative, } \\
\text { so it is subject to } \\
\text { change. }\end{array}$ & $\begin{array}{l}\text { They both have to } \\
\text { do with scientific } \\
\text { knowledge and the } \\
\text { potential for it to } \\
\text { change. }\end{array}$ \\
\hline 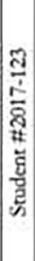 & 5 & $\begin{array}{l}\text { This is called global } \\
\text { warming. It has been } \\
\text { made a big deal that } \\
\text { human activities } \\
\text { have been destroying } \\
\text { the ozone layer } \\
\text { which effects } \\
\text { temperatures here on } \\
\text { earth. }\end{array}$ & 5 & $\begin{array}{l}\text { As more rescarch is } \\
\text { donc, new things can } \\
\text { be found. }\end{array}$ & 5 & $\begin{array}{l}\text { Research is } \\
\text { constantly being } \\
\text { done and being } \\
\text { tested. }\end{array}$ & $\begin{array}{l}\text { As new things are } \\
\text { found they are } \\
\text { tested and } \\
\text { researched further } \\
\text { and proved } \\
\text { accurate. }\end{array}$ \\
\hline
\end{tabular}

greater support for the tentative nature of science than the accuracy and trustworthiness of science, they still rate higher than the dissenters on both.

Turning to the climate change statement (Tables 14, 15), one again finds few dissenters (2015: $N=25 ; 2017: N=13)$. The percentage of dissenters declined slightly from 2015 to 2017 (from 8.3 to $6.4 \%$ ), an encouraging sign. Unlike for evolution, none of the dissenting comments mentioned religion, even though the demographic data we collected indicated that students regularly attending religious services showed less confidence in both human evolution and anthropogenic climate change (we will report more extensively on demographic connections in a separate paper). Rather, students dissenting to climate change gave alternative explanations involving physical causes for climate change. Somewhat like evolution, the 2015 dissenter comments on the durable yet tentative nature of science referred more to the tentative nature of science than to the durable nature of scientific knowledge, though some did acknowledge that scientific knowledge can be durable (e.g., Student 2015-44). In 2017, the climate dissenter comments were mostly about the tentative nature of science even when asked about the accuracy and trustworthiness of science.

As with evolution dissenters, we also looked separately at just the climate change dissenters. Data in the form of comments suggests that for these climate change dissenting students, a strong view on the tentative nature of science again seems to couple with lower confidence in the trustworthiness of science to fortify their dissent to climate change. Their 
comments track well with their Likert scores, and with the Likert score differences between those who strongly dissent from climate change and those who strongly accept it (Table 8). Unlike the contrast between evolution accepters and dissenters, views on the accuracy and trustworthiness of science are not that different between the climate change accepters and dissenters. Dissent from evolution is much stronger and coupled with a much lower view on the accuracy and trustworthiness of science.

The number of students accepting of the climate change statement (2015: $N=212 ; 2017$ : $N=147$ ) greatly outnumbered the dissenters. As discussed earlier in this paper, the comments in 2015 on the durable yet tentative nature of science primarily focused on the tentative nature of science even among these students strongly supporting the climate change statement. The 2017 students mostly addressed the accuracy and trustworthiness of science by commenting on the tentative nature of science rather than on what the statement actually said. However, while most of the comments were about the tentative nature of science, as one can see with Student 2017-123, students sometimes commented on the accuracy of scientific knowledge. As with the evolution accepting students, if there is a pattern in the comments made by students accepting of climate change it is likely that they primarily recognize the tentative nature of science but not at the expense of accuracy, though again, trust is not a preferred term. Once again, comments track well with Likert score means (Table 8). The strongest scores are for the tentative nature of science rather than the accuracy and trustworthiness of science.

\section{Conclusion}

Teaching about the nature of science is teaching about the attributes of scientific knowledge, and one fundamental attribute is uncertainty. Scientific knowledge is inherently uncertain; hence, we say that such knowledge should be considered tentative. In other words, uncertainty as an attribute of scientific knowledge is actionable in that we consider scientific claims to ultimately be tentative with respect to truth or accuracy. However, not all science is equally uncertain, or equally likely to undergo major revision.

With respect to public policy or personal decision-making, on matters where science is relevant, science educators will say that scientific knowledge is durable but also tentative. They will say that when this aspect of the nature of science is understood correctly, we see how and why science provides such an important and relatively reliable source of information for both public policy and personal decision-making.

However, this is not an argument one is likely to hear from public officials or generally in the public. Several of us involved with this research live in a Midwestern state where the governor acted early and decisively in response to the coronavirus threat, so much so that some considered her actions draconian. In defense of her actions, she frequently invoked science; but never did she do so by explaining that science is durable yet tentative. Rather, her invocation of science implied that scientific knowledge is accurate and therefore can be trusted as a basis for public policy in response to the epidemic.

By implication, her argument was based on the first part of this common statement about the nature of science: scientific knowledge is durable. Durability as an attribute of scientific knowledge is actionable in that we may consider scientific claims to be accurate and hence trustworthy, or at least to be our most accurate and trustworthy knowledge available about how the world works. Our governor implemented policy, unpopular among 
some, because she thought the relevant scientific knowledge was accurate and trustworthy enough to form a sound basis for her decisions.

We came to our research having observed both of the above perspectives on scientific knowledge. We know the science education community's various views on the nature of science and indeed we teach a fairly conventional model of the nature of science. We are, however, acutely aware that the public discourse is much different, where we hear such terms as "settled science" and "just a theory"; these observations gave rise to the possibility that, for some, emphasis on learning the tentative nature of science could be presenting the actionable option of declining to accept canonical science.

Bearing in mind the "just a theory" argument, we suggested that students who oppose or who are uncomfortable with controversial science concepts may bolster their doubts by turning to the inherently tentative nature of science. On the other hand, students who are confident in science may have a more nuanced view of the tentative nature of science. What we found was that almost all of the students embraced the tentative nature of science regardless of what they thought about controversial topics (hence, Hypothesis (1) was not rejected). Dissenters may use the tentative nature of science as an excuse for their dissent, but they don't appear to be substantially more likely to view science as tentative than other students. That is the good news. However, there was a clear and consistent divergence of confidence when the compound "durable yet tentative" idea was disaggregated into two separate themes.

Another actionable word based on the attribute of uncertainty is trust. Given the uncertainty of scientific knowledge, we may ask to what extent do we trust scientific knowledge for the purpose of taking other actions? Using a replication study (2017), we put this question to the test by replacing the word "durable" with the concept of trust. The findings were illuminating: many students apparently are not willing to say that they trust scientific knowledge. We expected that students who dissent from controversial science would demur on the trustworthiness of science, and they did, with evolution dissenters reporting the most startlingly low confidence in the accuracy and trustworthiness of science. Never did we think that students strongly supportive of science, including controversial science, would respond similarly. And why did they say that scientific knowledge is not trustworthy? Because it is tentative. That is the explanation offered and echoed by many students. They overlook even the degree of durability implicit in the word "knowledge."

Of course, many of our students who do not themselves avow trust in scientific knowledge are still likely supportive of our governor's actions, while not giving much thought to her trust in the science behind her coronavirus policies. What we suspect is that there is significant confusion around the terms used in the public (see, for example, Henig, 2020; Huber et al., 2019; Science, 2020) and indeed as used in science education concerning the nature of science.

We leave this study with implications for both instruction and research. In light of our findings, we think that it would be prudent for science educators to increase their instructional focus on the relationship between data and evidence that leads to the durability of scientific knowledge, and on how that exists in balance with the concept of tentativeness (e.g., see Hodson \& Wong, 2014). We also think it would be prudent to specifically raise with students the issue of trust, and relative trustworthiness, and what trust means with respect to the nature of science, and how these various terms about science are important in the public discussion on the use of science for the common good. But in doing so we should not forget that trust is an emotion.

As for future research, both our findings and the limitations of our study have research implications. Taken together, we think that there are four areas in which research could 
profitably be pursued. We think that various forms of replication are critical. The work we have done needs to be pursued through various types of replications involving different ways of expressing the concepts, different ways of asking the questions, and with various populations. Our research is limited by the population we studied (American, mostly white, mostly female, K-8 preservice teachers) and that suggests the need for replications of our study that would involve more diverse populations. Literature from public opinion research suggests that such replications should be done (see, for example, Funk et al., 2020).

Terminology is another area ripe for research. Our findings show that changing terms can have a significant impact on responses. We've already alluded to the word "durable" having no simple, straightforward definition among students. The NSTA position statement on the nature of science uses the word "reliable" instead of durable (NSTA, 2021). We've also noted that research communities outside of science education tend to use words like "uncertainty" instead of "tentative." Some synonyms, or alternatives, are likely to be better understood by the public, but as of yet, we have no clarity on how students or the rest of the public interpret all these various words with respect to science. Thus, we think it could be important to do semantics research on the impact of various terms on people's understanding of the nature of science. We also know very little about how trust in science might vary with one's knowledge of specific science disciplines. Our noncontroversial science statements were drawn from physics and the biological sciences. It would be advisable to replicate our study drawing from different areas of science as well as with different controversial issues, recognizing also that controversial scientific ideas can be highly culturally dependent.

Epistemology is the third area we think should be of interest regarding trust in scientific knowledge, given the likelihood that epistemological beliefs are related to how one understands the concept of durable yet tentative science. What is the basis, and what is the threshold, for qualifying and defending our private and public understandings as "knowledge"? There is a substantial body of work on epistemology related to science education that primarily dates back to Hofer and Pintrich (1997), Perry (1970), and Schommer (1990), including more recent work specifically addressing both epistemological belief and views of the nature of science (e.g., Cho et al., 2011; Huling, 2014; Koseoglu \& Köksal, 2015).

Our fourth suggestion for future research has to do with instruction. Our current research did not investigate the instructional backgrounds of each of these students with respect to the nature of science. We know of no such current research, and thus we recommend thorough investigations of the lingering effects of what we teach about the nature of science, how it is interpreted by students and the public at large, and what repercussions it might have on whether and how scientific knowledge is incorporated in the development and implementation of public policy. Science educators have become pretty good at avoiding the suggestion that scientific knowledge declares objective truths. Scientific knowledge nonetheless remains our most trustworthy resource about the objects and processes that it focuses intently upon, precisely because it focuses so intently upon them. Could it be that this important characteristic of science is somehow being overlooked amid all those other interesting characteristics? Missing the forest... for the trees?

We end this report acknowledging that scientific knowledge can never completely shed all uncertainty. We know that scientific claims are always going to be somewhat tentative. But uncertainty is not equally distributed across scientific knowledge claims... and it is certainly not equally distributed across all sources of knowledge and information. Whether one is an infectious disease expert, a state governor, or a science educator, we all need to find and share more clear and convincing answers to the question, "Why trust science?" 


\section{Declarations}

Conflict of interest The authors declare they have no conflict of interests

\section{References}

Adams, B. AJ, Cobern, W. W., \& Pleasants, B. A-S. (in preparation). Student definitions of 'durability' in the context of the nature of science.

Allchin, D. (2020). From science as "special" to understanding its errors and justifying trust. Science Education, (in press). https://doi.org/10.1002/sce.21571

American Academy of Arts \& Sciences. (2018). Perceptions of Science in America. American Academy of Arts \& Sciences. Retrieved 2021, October 27 from https://www.amacad.org/sites/default/files/ publication/downloads/PFoS-Perceptions-Science-America.pdf

American Association for the Advancement of Science (AAAS). (1990). Science for all americans online. american association for the advancement of science. Retrieved 2021, October 27 from http://www.project2061.org/publications/sfaa/online/chap1.htm

Bell, R. L., \& Lederman, N. G. (2003). Understandings of the nature of science and decision making on science and technology based issues. Science Education, 87(3), 352-377.

Branch, G., \& Mead, L. S. (2008). "Theory" in theory and practice. Evolution: Education and Outreach, 1(3), 287-289. https://doi.org/10.1007/s12052-008-0056-5

Carter, B. E., \& Wiles, J. R. (2014). Scientific consensus and social controversy: Exploring relationships between students' conceptions of the nature of science, biological evolution, and global climate change. Evolution: Education and Outreach, 7(1), 1-11.

Chhin, C. S., Taylor, K. A., \& Wei, W. S. (2018). Supporting a culture of replication: An examination of education and special education research grants funded by the Institute of Education Sciences. Educational Researcher, 47(9), 594-605.

Cho, M.-H., Lankford, D., \& Wescott, D. (2011). Exploring the relationships among epistemological beliefs, nature of science, and conceptual change in the learning of evolutionary theory. Evolution Education and Outreach, 4(2), 313-322.

Coyne, M. D., Cook, B. G., \& Therrien, W. J. (2016). Recommendations for replication research in special education: A framework of systematic conceptual replications. Remedial and Special Education, 37(4), 244-253.

Dewitt, R. (2018). Worldviews: An introduction to the history and philosophy of science (3rd ed.). Wiley Blackwell Publishing Limited.

Edelman, R. (2021). Edelman trust barometer 2021. Daniel J. Edelman, Inc. Retrieved 2021, January 23 from https://www.edelman.com/sites/g/files/aatuss191/files/2021-01/2021-edelmantrust-barometer. pdf

Ekman, P. (1992). An argument for basic emotions. Cognition and Emotion, 6(3-4), 169-200. https:// doi.org/10.1080/02699939208411068

Fasce, A., \& Picó, A. (2019). Science as a vaccine: The relation between scientific literacy and unwarranted beliefs [journal article]. Science \& Education, 28(1), 109-125. https://doi.org/10.1007/ s11191-018-00022-0

Friend, S., \& Tuddenham, H. (2015). Understanding the value and drivers of organisational trust: Trust insight. Pricewaterhouse Coopers LLP. Retrieved 2021, August 12 from https://www.pwc.com/my/ en/assets/trust/trust-insight-understanding-the-value-and-drivers-of-organisational-trust.pdf

Funk, C. (2017). Mixed messages about public trust in science. Issues in Science and Technology, 34(1), 86-88 http://www.jstor.org.libproxy.library.wmich.edu/stable/44577388

Funk, C., \& Kennedy, B. (2020). How Americans see climate change and the environment in 7 charts. Pew Research Center. Retrieved 2021, February 5 from https://www.pewresearch.org/fact-tank/ 2020/04/21/how-americans-see-climate-change-and-the-environment-in-7-charts/

Funk, C., Tyson, A., Kennedy, B., \& Johnson, C. (2020). Science and scientists held in high esteem across global publics. Retrieved 2021, August 12 from https://www.pewresearch.org/science/2020/ 09/29/science-and-scientists-held-in-high-esteem-across-global-publics/

Gustafson, A., \& Rice, R. E. (2020). A review of the effects of uncertainty in public science communication. Public Understanding of Science, 29(6), 614-633. https://doi.org/10.1177/0963662520942122 
Hardwig, J. (1991). The role of trust in knowledge. The Journal of Philosophy, 88(12), 693-708. http:// www.jstor.org/stable/2027007? origin=JSTOR-pdf

Henig, R. M. (2020). In science we must trust. National Geographic, 238(5), 56-65.

Hodson, D., \& Wong, S. L. (2014). From the Horse's Mouth: Why scientists' views are crucial to nature of science understanding. International Journal of Science Education, 36(16), 2639-2665.

Hofer, B., \& Pintrich, P. (1997). The development of epistemological theories: Beliefs about knowledge and knowing and their relation to learning. Review of Educational Research, 67, 88-140.

Huber, B., Barnidge, M., Gil de Zúñiga, H., \& Liu, J. (2019). Fostering public trust in science: The role of social media. Public Understanding of Science, 28(7), 759-777. https://doi.org/10.1177/09636 62519869097

Huling, M. D. (2014). The effect of teachers' epistemological beliefs on practice. University of South Florida scholarcommons.usf.edu/etd/5044

Johnson-Laird, P. N., \& Oatley, K. (1989). The language of emotions: An analysis of a semantic field. Cognition \& Emotion, 3(2), 81-123 http://www.tandfonline.com/loi/pcem20

Koseoglu, P., \& Köksal, M. S. (2015). Epistemological predictors of prospective biology teachers' nature of science understandings. Eurasian Journal of Science and Technology Education, 11(4), 751-763 https://www.ejmste.com/download/epistemological-predictors-of-prospective-biologyteachers-nature-of-science-understandings-4412.pdf

Kuhn, T. S. (1957). The Copernican revolution: Planetary astronomy in the development of western thought. Harvard University Press.

Lederman, N. G., \& Lederman, J. S. (2014). Research on teaching and learning of nature of science. In: N. G. Lederman, \& S. K. Abell (Eds.), Handbook of research on science education (Vol. II, pp. 600-620). Routledge.

Lombrozo, T. (2012). Is Evolution "Just a Theory"? Post \#3 in a series for Darwin Day 2012. Psychology Today. Retrieved 2021, October 27 from https://www.psychologytoday.com/us/blog/explananda/ 201202/is-evolution-just-theory

Macebo, S. (2019). Introduction. In In Why Trust Science? (pp. 1-14) Princeton University Press.

Makel, M. C., \& Plucker, J. A. (2014). Facts are more important than novelty: Replication in the education sciences. Educational Researcher, 43(6), 304-316.

Masci, D. (2019). For Darwin Day, 6 facts about the evolution debate. Pew Research Center. Retrieved 2021, February 5 from https://www.pewresearch.org/fact-tank/2019/02/11/darwin-day/

Massimi, M. (2019). Getting it right: Truth is neither absolute nor timeless. But the pursuit of truth remains at the heart of the scientific endeavour. aeon.com. Retrieved 2020, October 28 from https:// aeon.co/essays/its-time-for-a-robust-philosophical-defence-of-truth-in-science

McComas, W. F. (1998). The nature of science in science education: Rationales and strategies. Kluwer Academic Publishers.

McComas, W. (2020). Nature of science in science instruction: Rationales and strategies (2nd ed.). Springer Academic Publishers.

Merriam-Webster. (2021). Merriam-Webster Thesaurus. Merriam-Webster, Incorporated. Retrieved 2021, October 27 from https://www.merriam-webster.com/thesaurus

Miller, K. R. (2008). Only a theory: Evolution and the battle for America's soul. Penguin Books.

Nadelson, L. S., \& Hardy, K. K. (2015). Trust in science and scientists and the acceptance of evolution. Evolution: Education and Outreach, 8(1), 9. https://doi.org/10.1186/s12052-015-0037-4

Nadelson, L., Jorcyk, C., Yang, D., Jarratt Smith, M., Matson, S., Cornell, K., \& Husting, V. (2014). I just don't trust them: The development and validation of an assessment instrument to measure trust in science and scientists. School Science and Mathematics, 114(2), 76-86. https://doi.org/10.1111/ ssm. 12051

Nature. (2017). School daze: As US states turn the screw on science education, researchers everywhere should pay more attention to how their subject is presented. Nature., 543, 149.

National Science Teachers Association. (2021). An NSTA position statement: Nature of Science. NSTA. Retrieved 2021, October 27 from https://www.nsta.org/nstas-official-positions/naturescience

Ogawa, M. (1986). A preliminary study on a key concept "nature" involved in science education. The Bulletin of the Faculty of Education, Ibaraki University (Educational Sciences) (In Japanese with English abstract), 35, 1-8.

Oreskes, N. (2004). The scientific consensus on climate change. Science, 306(5702), 1686-1686. https:// doi.org/10.1126/science. 1103618

Oreskes, N. (2019). Why trust science? Princeton University Press.

Perla, R. J., \& Carifio, J. (2008). Can our conception of the nature of science be tentative without qualification? The Journal of Educational Thought (JET) / Revue de la Pensée Éducative, 42(2), 127-150. https://doi.org/10.11575/jet.v42i2.52460 
Perry, W. G. (1970). Forms of intellectual and ethical development in the college years: A scheme. Rinehart and Winston Inc..

Pew Research Center. (2021). Tools \& resources. Pew Research Center. Retrieved 2021, August 12 from https://www.pewresearch.org/tools-and-resources/

Pittinsky, T. L. (2015). America's crisis of faith in science. Science, 348(6234), 511-512.

Plutchik, R. (2001). The Nature of Emotions: Human emotions have deep evolutionary roots, a fact that may explain their complexity and provide tools for clinical practice. American Scientist, 89(4), 344-350 http://www.jstor.org/stable/27857503

Reiersen, J. (2017). Trust as belief or behavior? Review of Social Economy, 75(4), 434-453. https://doi. org/10.1080/00346764.2016.1269939

Sanz-Menéndez, L., \& Cruz-Castro, L. (2019). The credibility of scientific communication sources regarding climate change: A population-based survey experiment. Public Understanding of Science, 28(5), 534-553. https://doi.org/10.1177/0963662519840946

Schmidt, S. (2009). Shall we really do it again? The powerful concept of replication is neglected in the social sciences. Review of General Psychology, 13(2), 90-100.

Schommer, M. (1990). Effects of beliefs about the nature of knowledge on comprehension. Journal of Educational Psychology, 82(3), 498-504.

Science. (2020). News at a glance: U.S. leads in science trust gulf. Science (AAAS), 370(6512), 14-15. https://doi.org/10.1126/science.370.6512.14

Taber, K. S. (2018). The use of Cronbach's Alpha when developing and reporting research instruments in science education. Research in Science Education, 48(6), 1273-1296. https://doi.org/10.1007/ s11165-016-9602-2

Toulmin, S. G. J. (1961). The fabric of the heavens: The development of astronomy and dynamics. Harper and Row.

Weisberg, D. S., Landrum, A. R., Hamilton, J., \& Weisberg, M. (2020). Knowledge about the nature of science increases public acceptance of science regardless of identity factors. Public Understanding of Science. https://doi.org/10.1177/0963662520977700

Publisher's Note Springer Nature remains neutral with regard to jurisdictional claims in published maps and institutional affiliations.

\section{Authors and Affiliations}

\section{William W. Cobern ${ }^{1}$ (D) Betty AJ Adams ${ }^{1} \cdot$ Brandy A-S. Pleasants $^{1} \cdot$ Andrew Bentley $^{2}$. Robert Kagumba ${ }^{3}$}

1 The Mallinson Institute for Science Education, Western Michigan University, Kalamazoo, MI, USA

2 The University of Pittsburgh, Pittsburgh, PA, USA

3 Kalamazoo, MI, USA 